\title{
Evaluating the Effectiveness of Orthognathic Surgery on the Pre-existing Temporomandibular Disorders in Patients with Malocclusion: A Systematic Review and Meta-analysis
}

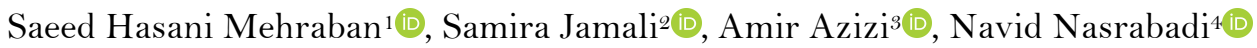

\begin{abstract}
${ }^{1}$ Department of Oral and Maxillofacial Surgery, School of Dentistry, Tehran University of Medical Sciences, Tehran, Iran.

${ }^{2}$ Department of Endodontics, Stomatological Hospital, College of Stomatology, Xi'an Jiaotong University, Shaanxi, China.

${ }^{3}$ Department of Prosthodontics, School of Dentistry, Alborz University of Medical Sciences, Karaj, Iran.

${ }^{4}$ Department of Endodontics, School of Dentistry, Shahid Beheshti University of Medical Sciences, Tehran, Iran.
\end{abstract}

Author to whom correspondence should be addressed: Samira Jamali, Department of Endodontics, Stomatological Hospital, College of Stomatology, Xi'an Jiaotong University, Shaanxi 710004, PR China. E-mail: samira.jamali90@yahoo.com.

Academic Editor: Alessandro Leite Cavalcanti

Received: 02 March 2020 / Accepted: 20 April 2020 / Published: 16 July 2020

How to cite this article: Mehraban SH, Jamali S, Azizi A, Nasrabadi N. Evaluating the effectiveness of orthognathic surgery on the pre-existing temporomandibular disorders in patients with malocclusion: a systematic review and metaanalysis. Pesqui Bras Odontopediatria Clín Integr. 2020; 20:e0035. https://doi.org/10.1590/pboci.2020.138

\begin{abstract}
Objective: To evaluate the prevalence of temporomandibular disorders (TMDs) for those patients with dentofacial deformities, who underwent orthognathic surgery, and the control group. It also identified whether orthognathic surgery had a positive or negative impact on TMD symptoms by comparing TMD patients, who underwent orthognathic surgery, and people did not experience this surgery. Finally, this systematic review and meta-analysis aimed to evaluate the effectiveness of orthognathic surgery on the preexisting TMDs in malocclusion patients. Material and Methods: MEDLINE, PubMed, Cochrane Library, Embase, ISI, google scholar have been utilized as the electronic databases for systematically reviewing the literature between 2001 and February 2019. Inclusion criteria were undergoing orthognathic surgery, patients with/without pre-existing TMDs, and physical disabilities. Results: A total of 669 abstracts and titles with potential relevance have been identified in the course of the manual and electronic searches. It has been found that five studies met our inclusion criteria for a systematic review. Temporomandibular disorders (TMDs) before orthognathic surgery in comparison to the controls ( $\mathrm{RR}=0.02$; 95\% CI -0.08-0.13) and heterogeneity among the papers has been $\mathrm{I} 2=42.86 \%(\mathrm{p}=0.64)$. Conclusion: Malocclusion by orthognathic and orthodontics surgeries had a considerable rate of TMD compared to the controls.
\end{abstract}

Keywords: Malocclusion; Orthognathic Surgery; Temporomandibular Joint Disorders. 


\section{Introduction}

The research confirmed that it is possible to characterize temporomandibular disorders (TMD) as an assortment of symptoms kept to temporomandibular joint (TMJ) and the pertinent structures. Therefore, such symptoms might incorporate tenderness of mastication muscles, headache, neck and facial pain, TMJ pain, limitations in the opening of the mouth, dentition wear, jaw locking, par-functional habits, and otalgia [1].

There was clashing information to the predominance of the TMD symptoms. Several studies showed the increased prevalence of TMD symptoms in patients with dentofacial distortion, changing between $40.8 \%$ and $97 \%$ [2,3]. Besides, some authors published a decreased rate in the range between $14 \%$ and $26.5 \%$ [2]. TMD prevalence in patients who experienced a particular dentofacial deformity (i.e., Class III and Class II) has a higher prevalence than the general population [4]. However, there are many debates on the affiliation between pre-existing TMD in patients with dentofacial deformities and their treatment with orthognathic surgical operation [2].

Some researchers claimed that orthognathic surgery would have an advantageous impact on the preexisting TMDs [5], or at the slightest level did not irritate the pre-existing conditions [6,7]. Still, others claimed a combination of the pre-existing TMD by orthognathic surgery [8].

Furthermore, the authors discussed the effect of orthognathic surgery on TMD symptoms in maxillofacial and oral surgeries. A few research also detailed the diminished symptoms of TMD of the orthognathic surgery as a result of the improvements in the occlusal stability or lower emotional stresses [9]. Others demonstrated a declining [8] or lack of changes in the TMDs following the orthognathic surgery [7], negative or positive impact on TMDs symptoms [10], assessment of TMD pervasiveness for patients with dentofacial deformity who underwent the orthognathic surgery in comparison to the controls, and identification of the issue whether orthognathic surgery included negative or positive impacts on TMD symptoms via making a comparison between the TMD patients who underwent the orthognathic surgery and those who did not $[2,11,12]$. Therefore, the present systematic review and meta-analysis aimed at evaluating the effective orthognathic surgery on the pre-existing TMD in malocclusion patients.

\section{Material and Methods}

Search Strategy

MEDLINE, PubMed, Cochrane Library, Embase, ISI, and Google scholar have been utilized as the electronic databases for a systematic literature review between 2001 and February 2019. Therefore, Endnote $\mathrm{X} 9$, one of the commercially available software programs, has been utilized to manage the titles electronically. Hence, we searched the keywords of "Orthognathic Surgery," "Temporomandibular Disorders OR TMD," "Malocclusion," "Class III," and "Class II." Notably, this systematic review has been conducted based on the main consideration of the PRISMA Statement (the Preferred Reporting Items for Systematic Reviews \& Metaanalysis) [13]. PICOS strategy showed in Table1.

\section{Table1. PICOS strategy.}

\begin{tabular}{|c|c|c|}
\hline $\mathrm{P}$ & Patients & Patients were undergoing orthognathic surgery with various dentofacial deformities. \\
\hline I & Intervention & Patients with/without pre-existing TMDs. \\
\hline $\mathrm{C}$ & Compare & $\begin{array}{l}\text { Patients with no congenital distortions, physical inabilities, previous jaw surgery, and great } \\
\text { maxillomandibular relations and normal occlusion. }\end{array}$ \\
\hline $\mathrm{O}$ & Outcomes & Report all Outcomes for TMD subgroups. \\
\hline $\mathrm{S}$ & Study Design & $\begin{array}{l}\text { Randomized controlled trials studies, prospective and retrospective cohort studies, and controlled } \\
\text { clinical trials. }\end{array}$ \\
\hline
\end{tabular}




\section{Selection Criteria}

The following inclusion criteria were established: 1) The randomized controlled trials studies, prospective and retrospective cohort studies, and controlled clinical trials; 2) Studies conducted on humans; 3) Undergoing orthognathic surgery; 4) Patients with/without pre-existing TMDs; 5) Patients with physical disabilities; 6) Patients with earlier jaw surgeries; 7) Patients with suitable maxillo-mandibular relation and normal occlusion; 8) TMDs symptoms in the patients who underwent orthognathic surgery; 9) Studies with the control groups, and 10) Studies written in English.

The following exclusion criteria were established: 1) In-vitro studies, case reports, reviews, and case studies; 2) Animal studies; 3) Patients with mandibular condyle; 4) Patients with the treatments done for TMJ; 5) Patients with trauma or clefts; 6) Patients with the congenital malformation and craniofacial syndrome, and

7) Patients with systemic arthritis or muscular diseases.

\section{Data Extraction and Method of Analysis}

In this stage, data have been extracted from the research, which involved study, years, study design, follow-up period, sample size, male or female ratio, range and mean of age, dentofacial deformities, outcomes, and conclusion. A study that included all the domains was classified as having a low risk of bias, a study that was missing one of these domains was classified as having a moderate risk of bias. When two or more domains were missing, the study was considered to have a high risk of bias. Moreover, the risk ratio (RR) have been analyzed by meta-analysis. RR of signs and symptoms of TMDs before and after orthognathic surgery. Distribution of various symptoms of TMD was divided into nine subgroups (One or more subjective symptoms, Joint clicking, Joint crepitation, Muscle palpation tenderness, Joint pain on palpation, Limited opening, Deviation on mouth opening, Headache, Grinding). The risk ratio with corresponding $95 \%$ confidence intervals (95\% CIs) and effects model with 95\% confidence intervals [CI] was performed. Then, the forest plots have been evaluated with Comprehensive Meta-Analysis Stata/MP 16.0.

\section{Results}

While electronically and manually searching, we discovered a total number of 669 potentially pertinent abstracts and topics. In the course of the first phase of the study selection, 606 investigations were excluded based on abstracts and titles. Then, full-text papers of other 54 studies have been fully assessed. It has been found that 49 articles should be excluded due to lack of the satisfaction with the inclusion criteria of this review. Ultimately, five researches met our inclusion criteria to conduct a systematic review (Figure 1).

Five studies (prospective) have been included in this review, including a total of 627 patients (Group 1 $=350$ and Group $2=277$ ) with a mean age of Group 1 that equalled to 25.78 years and Group 2 equalled to 24.54 years. The Follow-up period ranged from 1 week to 24 months. Dentofacial deformities have been in Class III (159), Class II (43), and Class I (24) (Table 2). Table 3 presents the risk of bias in the studies selected for meta-analysis.

TMDs before orthognathic surgery compared to the controls, there was no significant difference between the two groups. The risk ratio was $(\mathrm{RR}=0.02 ; 95 \% \mathrm{CI}-0.08-0.13)$ and heterogeneity among the papers has been $\mathrm{I} 2=42.86 \% \mathrm{p}=0.64$ (Figure 2 ). In addition, the risk ratio for TMDs after orthognathic surgery compared with a control group has been -0.03; 95\% CI -0.10-0.04; Furthermore, the heterogeneity among these papers equaled $\mathrm{I} 2=0 \% ; \mathrm{p}=0.41$ (Figure 3 ). 


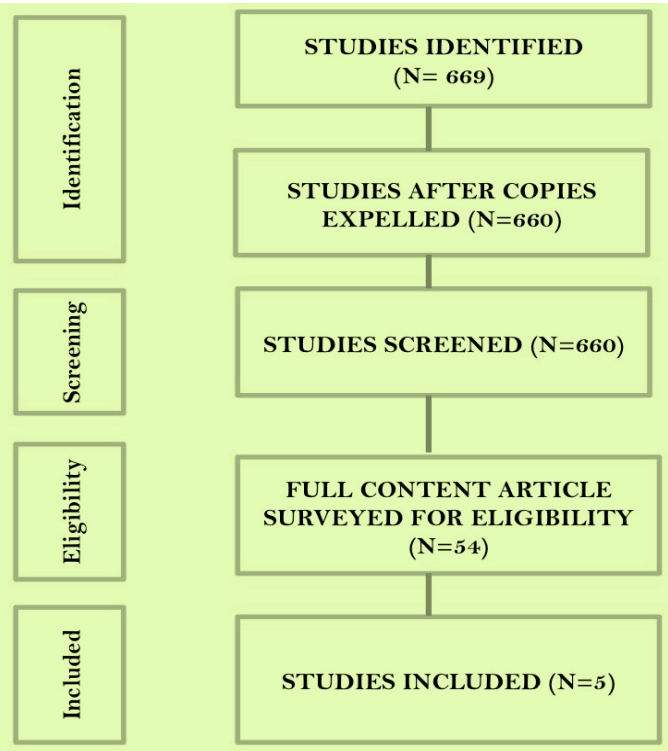

\section{STUDIES EXCLUDED $(\mathrm{N}=606)$}

FULL CONTENT ARTICLE

EXCLUDED ( $N=49)$

Figure 1. Study attrition diagram.

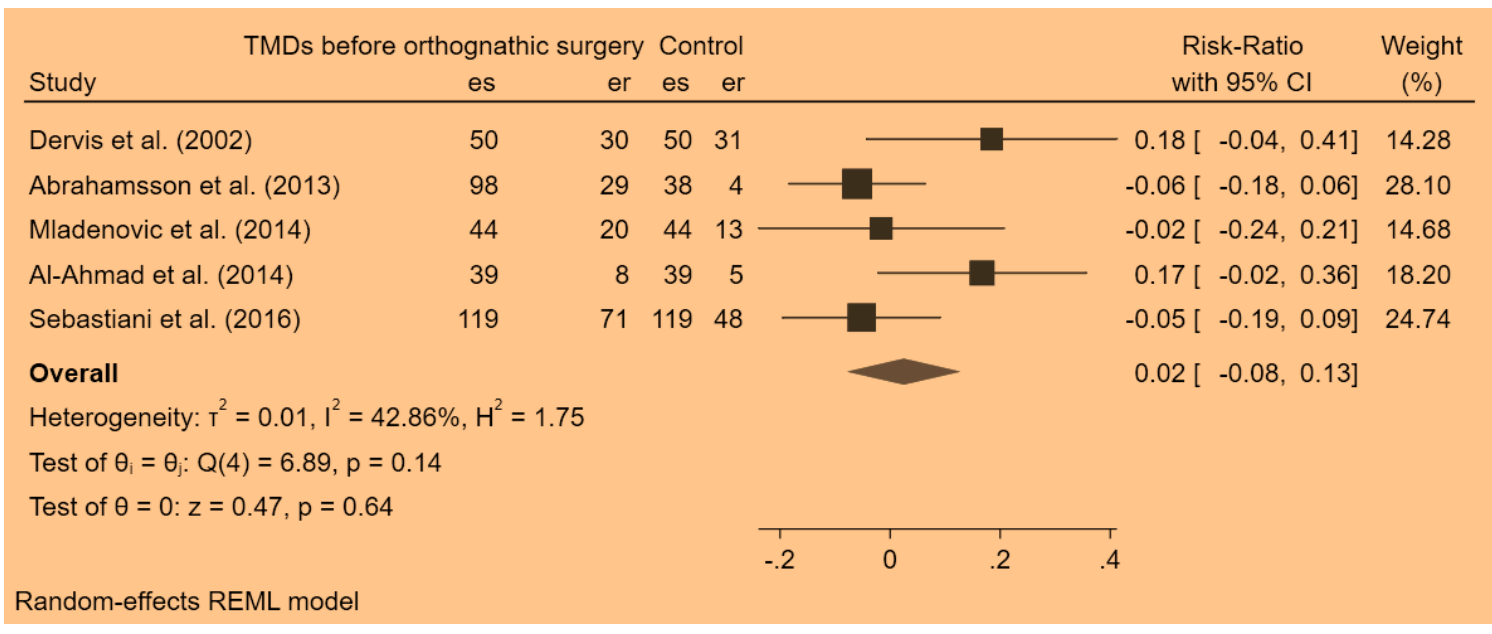

Figure 2. Forest plots showed TMDs before orthognathic surgery (Es: Effect Size; Er: Event Rate).

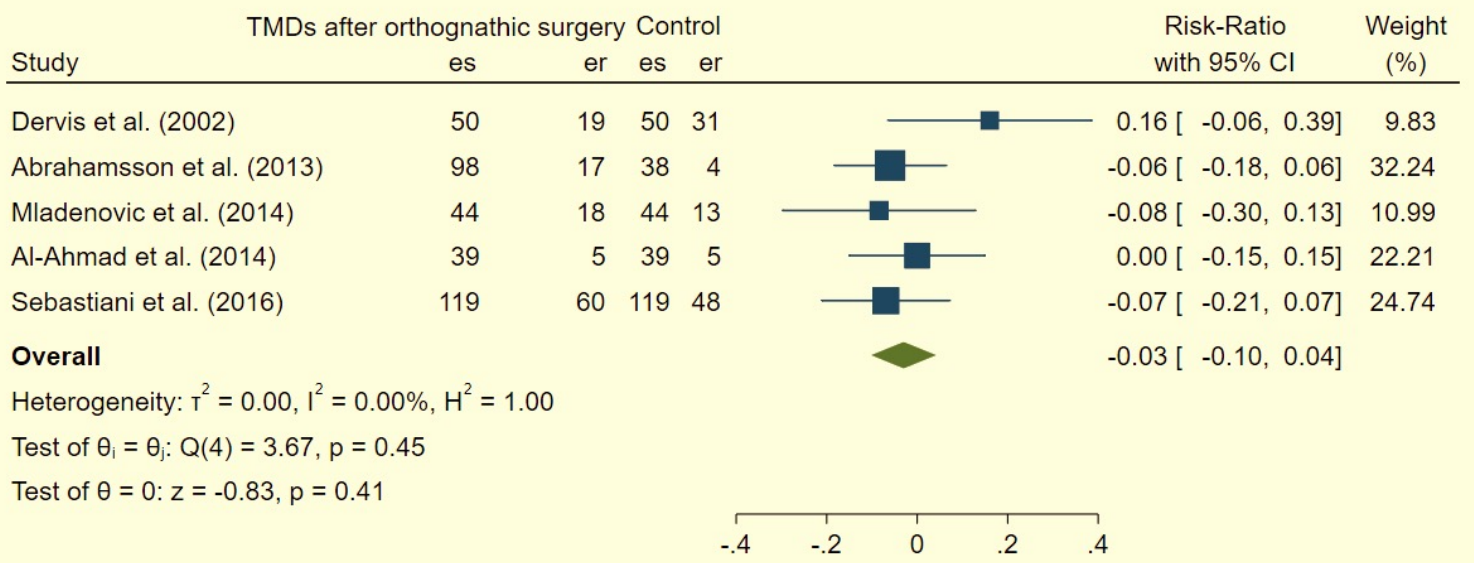

Random-effects REML model

Figure 3. Forest plots showed TMDs after orthognathic surgery (Es: Effect Size; Er: Event Rate). 


\begin{tabular}{|c|c|c|c|c|c|c|c|c|c|c|c|c|c|c|}
\hline \multirow[b]{2}{*}{ Study/Year } & \multirow[t]{2}{*}{ Design } & \multicolumn{2}{|c|}{$\begin{array}{l}\text { Sample } \\
\text { Size }\end{array}$} & \multicolumn{2}{|c|}{ Male } & \multicolumn{2}{|c|}{ Female } & \multicolumn{2}{|c|}{ Age } & \multirow[t]{2}{*}{$\begin{array}{l}\text { Follow-up } \\
\text { Period }\end{array}$} & \multicolumn{3}{|c|}{$\begin{array}{l}\text { Dentofacial } \\
\text { Deformities }\end{array}$} & \multirow[b]{2}{*}{ Conclusions } \\
\hline & & G 1 & G2 & G 1 & G2 & G 1 & $\mathrm{G}_{2}$ & G 1 & G2 & & $\begin{array}{c}\text { Class } \\
\text { III }\end{array}$ & $\begin{array}{l}\text { Class } \\
\text { II }\end{array}$ & $\begin{array}{c}\text { Class } \\
\text { I }\end{array}$ & \\
\hline $\begin{array}{c}\text { Dervis et al. (2002) } \\
{[14]}\end{array}$ & Prospective & 50 & 50 & 21 & 29 & 22 & 28 & 29.3 & 29.8 & $\begin{array}{c}1 \mathrm{w} \\
12 \mathrm{~m} \\
24 \mathrm{~m}\end{array}$ & & $\mathrm{NA}$ & & $\begin{array}{l}\text { Not Statistical differences } \\
\text { between symptoms and the } \\
\text { type of dentofacial deformity }\end{array}$ \\
\hline $\begin{array}{l}\text { Abrahamsson et al. } \\
\quad(2013)[15]\end{array}$ & Prospective & 98 & 38 & 38 & 23 & 60 & 33 & 22.4 & 23.4 & $18 \mathrm{mo}-24 \mathrm{mo}$ & 58 & 20 & 13 & $\begin{array}{l}\text { The positive effects of the } \\
\text { treatment on the TMD pain }\end{array}$ \\
\hline $\begin{array}{l}\text { Mladenovic et al. } \\
\quad(2014)[16]\end{array}$ & Prospective & 44 & 44 & 25 & 19 & 25 & 19 & 23.2 & 23.5 & NR & 44 & - & - & $\begin{array}{l}\text { TMD in class III dentofacial } \\
\text { deformities had the same rate } \\
\text { of prevalence. }\end{array}$ \\
\hline $\begin{array}{l}\text { Al-Ahmad et al. } \\
\text { (2014) [17] }\end{array}$ & Prospective & 39 & 39 & 12 & 17 & 21 & 18 & 23.8 & 23 & $21 \mathrm{mo}$ & 24 & 6 & 7 & $\begin{array}{l}\text { TMDs following the } \\
\text { treatment could negatively } \\
\text { influence life quality. }\end{array}$ \\
\hline $\begin{array}{l}\text { Sebastiani et al. } \\
\quad(2016)[18]\end{array}$ & Retrospective & 119 & 106 & 10 & 7 & 35 & 2 & 30.2 & 23 & 6-12mo & 33 & 17 & 4 & $\begin{array}{l}\text { Statistical differences for pre- } \\
\text { surgery and post-surgery } \\
\text { outcomes were not clearly } \\
\text { reported. }\end{array}$ \\
\hline
\end{tabular}

Table 3. Risk of bias.

\begin{tabular}{lcccccc}
\hline \multicolumn{1}{c}{ Study/Year } & Random Selection & $\begin{array}{c}\text { Defined Inclusion/ } \\
\text { Exclusion Criteria }\end{array}$ & $\begin{array}{c}\text { Loss to } \\
\text { Follow-Up }\end{array}$ & $\begin{array}{c}\text { Validated } \\
\text { Measurement }\end{array}$ & $\begin{array}{c}\text { Statistical } \\
\text { Analysis }\end{array}$ & $\begin{array}{c}\text { The Estimated } \\
\text { Potential Risk of Bias }\end{array}$ \\
\hline Dervis et al. (2002) $[14]$ & Yes & Yes & Yes & Yes & Yes & Low \\
Abrahamsson et al. (2013) $[15]$ & No & Yes & Yes & Yes & Yes & Moderate \\
Mladenovic et al. (2014) $[16]$ & No & Yes & Yes & Yes & Yes & Moderate \\
Al-Ahmad et al. (2014) $[17]$ & No & Yes & Yes & Yes & Yes & Moderate \\
Sebastiani et al. (2016) $[18]$ & No & Yes & Yes & Yes & Yes & Moderate \\
\hline
\end{tabular}




\section{Discussion}

In this systematic review meta-analysis, there were no differences in TMD pervasiveness in the patients with dentofacial deformity before the treatment. Some studies showed improvements in the TMDs symptoms. Particularly, pain declined following orthognathic surgery [15,19]. In addition, malocclusion caused TMDs in numerous patients so that aggravated malocclusion healed the TMDs. Unfortunately, that the conducted studies did not accept this simplistic justification. Therefore, to reply to a few of the above questions, it is necessary to investigate the multifactorial etiologies of TMDs. Therefore, analyses did not confirm the correlation between TMD and occlusal condition. However, there has been not a new approach to establishing a weak relationship between a specific occlusal interferer and TMDs [20-22].

Some studies reject this point that malocclusion alone can cause TMD [20,21,23], but certain forms of crossbites [24], as well as profound chomps [25], could play a part in declining a few TMJ symptoms [26,27]. Previous authors determined the prevalence of the symptoms of temporomandibular disorders in adolescents and children with and without crossbites [28]. Hence, TMD frequency could be compared in two groups at follow-up sessions. Another study demonstrated that patients with dentofacial deformities corrected by the orthodontic treatments related to orthognathic surgery exhibited a positive treatment impact on TMD pains [15]. Consequently, this systematic review and meta-analysis reported no differences in TMD pervasiveness in the patients suffering from dentofacial deformity after treatment. However, numerous investigations discussed condyle disc relationships and orthognathic surgery [29].

There is enough information about the alterations in the disc position following the mandibular osteotomy [30]. Such changes in the position could justify the reason for relieving aches within the TMJ following the corrective jaw surgery; however, other authors recommended it as one of the plausible sources of relapse [29]. Besides, some researchers utilized osteotomies or altered condylotomy and approved its contribution to reducing the pain within TMJ, particularly in the patients with the disc displacement. However, there has been no adequate data of if alterations in the disc position following the orthognathic surgery could contribute to the relief or preservation of TMD [31].

Previous authors assessed the effects of the orthognathic surgical treatments on the TMD, quality of life (QoL), and psychosocial well-being [32]. They discovered that psychological parameters and TMD strongly influenced the life quality of the patients compared to the objective treatment outcome measure. However, this has been exceptionally conceivable: before surgical operations, the patients have been disappointed with their appearances and had lower self-esteem, which induced TMD. Therefore, enhancement in the cosmetic appearances following the surgical operation and the consequent impact on the patients, in general confidence and psychological images, could diminish depression and stress that made a difference in the control of a number of the subjective aspects of TMD [12,33].

It is notable that the systematic review and meta-analysis previously conducted [2] dealt with this question "Do patients with malocclusion exhibit a greater prevalence of TMDs than the control group before and following the orthognathic surgery". The researchers showed that patients with the corrected malocclusion by orthognathic or orthodontics surgeries had a considerable rate of incidence of TMD in comparison with the controls. These results are consistent with the present study. It is exceptionally conceivable that patients are dissatisfied with their appearance before surgery and have lower self-esteem, in which these components induce TMDs. Advancement in cosmetic appearance after surgery and its subsequent impact on patients' overall confidence and psychological image may decrease stress and depression, making a difference in controlling some of the subjective aspects of TMDs. 


\section{Conclusion}

Findings demonstrated that malocclusion by orthognathic and orthodontics surgeries had a considerable rate of TMD in comparison with the controls. Following the treatment, TMD frequency did not vary from the frequencies seen in the controls.

\section{Authors' Contributions}

\begin{tabular}{|c|c|c|}
\hline SHM & (D) $0000-0002-8333-8511$ & Writing - Original Draft Preparation and Writing - Review and Editing. \\
\hline SJ & (D) $0000-0003-3803-1235$ & $\begin{array}{l}\text { Conceptualization, Methodology, Software, Investigation, Formal Analysis, } \\
\text { Writing - Original Draft Preparation, Writing - Review and Editing and } \\
\text { Supervision. }\end{array}$ \\
\hline AA & (D) $0000-0001-7280-5500$ & Writing - Original Draft Preparation and Writing - Review and Editing. \\
\hline $\mathrm{NN}$ & (D) $0000-0002-6365-6619$ & Writing - Original Draft Preparation and Writing - Review and Editing. \\
\hline
\end{tabular}

\section{Financial Support}

None.

\section{Conflict of Interest}

The authors declare no conflicts of interest.

\section{References}

[1] Luther F, Layton S, McDonald F. Orthodontics for treating temporomandibular joint (TMJ) disorders. Cochrane Database Syst Rev 2016; (1):CD006541. https://doi.org/10.1002/1465 1858.CD006541.pub3

[2] Al-Moraissi EA, Perez D, Ellis III E. Do patients with malocclusion have a higher prevalence of temporomandibular disorders than controls both before and after orthognathic surgery? a systematic review and meta-analysis. J Craniomaxillofac Surg 2017; 45(10):1716-23. https://doi.org/10.1016/j.jcms.2017.07.015

[3] Kretschmer WB, Baciuţ G, Baciuţ M, Sader R. Effect of bimaxillary orthognathic surgery on dysfunction of the temporomandibular joint: a retrospective study of 500 consecutive cases. Br J Oral Maxillofac Surg 2019; 57(8):734-9. https://doi.org/10.1016/j.bjoms.2019.06.010

[4] Lindfors E, Arima T, Baad-Hansen L, Bakke M, Laat A, Giannakopoulos NN, et al. Jaw exercises in the treatment of temporomandibular disorders--an international modified delphi study. J Oral Facial Pain Headache 2019; 33(4):38998. https://doi.org/10.11607/ofph.2359

[5] Ezhil I, Arun AV, Kumar MP. Morphological changes of the mandibular condyle following orthodontic treatment. Drug Invent Today 2018; 10(1):2802-4.

[6] Fisher B. Temporomandibular Joint Outcomes Following Orthognathic Surgery. [Dissertation]. Nova Scotia: Dalhousie University; 2018.

[7] Firoozei G, Shahnaseri S, Momeni H, Soltani P. Evaluation of orthognathic surgery on articular disc position and temporomandibular joint symptoms in skeletal class II patients: a magnetic resonance imaging study. J Clin Exp Dent 2017; 9(8):e976-e980. https://doi.org/10.4317/jced.53824

[8] Näpänkangas R, Raunio A, Sipilä K, Raustia A. Effect of mandibular advancement device therapy on the signs and symptoms of temporomandibular disorders. J Oral Maxillofac Res 2013; 3(4):e5. https://doi.org/10.5037/jomr.2012.3405

[9] Celakil D, Ozdemir F, Eraydin F, Celakil T. Effect of orthognathic surgery on masticatory performance and muscle activity in skeletal Class III patients. Cranio 2018; 36(3):174-80. https://doi.org/10.1080/08869634.2017.1311395

[10] Morell GFC. Insufficient evidence to support or reject effect of conservative TMD therapies on otologic signs and symptoms. Evid Based Dent 2018; 19(1):26-7. https://doi.org/10.1038/sj.ebd.6401293

[11] Al-Moraissi EA, Wolford LM, Perez D, Laskin DM, Ellis III E. Does orthognathic surgery cause or cure temporomandibular disorders? a systematic review and meta-analysis. J Oral Maxillofac Surg 2017; 75(9):1835-47. https://doi.org/10.1016/j.joms.2017.03.029

[12] Sebastiani AM, Corso PFCL, Bonotto D, Souza JF, Costa DJ, Scariot R, et al. Does orthognathic surgery improve myofacial pain in individuals with skeletal class III? One-year follow-up. Oral Surg Oral Med Oral Pathol Oral Radiol 2018; 126(4):322-30. https://doi.org/10.1016/j.00oo.2018.03.020 
[13] Panic N, Leoncini E, De Belvis G, Ricciardi W, Boccia S. Evaluation of the endorsement of the preferred reporting items for systematic reviews and meta-analysis (PRISMA) statement on the quality of published systematic review and meta-analyses. PLoS One 2013; 8(12):e83138. https://doi.org/10.1371/journal.pone.0083138

[14] Dervis E, Tuncer E. Long-term evaluations of temporomandibular disorders in patients undergoing orthognathic surgery compared with a control group. Oral Surg Oral Med Oral Pathol Oral Radiol Endod 2002; 94(5):554-60. https://doi.org/10.1067/moe.2002.128021

[15] Abrahamsson C, Henrikson T, Nilner M, Sunzel B, Bondemark L, Ekberg EC. TMD before and after correction of dentofacial deformities by orthodontic and orthognathic treatment. Int J Oral Maxillofac Surg 2013; 42(6):752-8. https://doi.org/10.1016/j.ijom.2012.10.016

[16] Mladenović I, Dodić S, Stošić S, Petrović D, Čutović T, Kozomara R. TMD in class III patients referred for orthognathic surgery: psychological and dentition-related aspects. J Craniomaxillofac Surg 2014; 42(8):1604-9. https://doi.org/10.1016/j.jcms.2014.04.029

[17] Al-Ahmad HT, Al-Bitar ZB. The effect of temporomandibular disorders on condition-specific quality of life in patients with dentofacial deformities. Oral Surg Oral Med Oral Pathol Oral Radiol 2014; 117(3):293-301. https://doi.org/10.1016/j.oooo.2013.11.493

[18] Scolozzi P, Wandeler PA, Courvoisier DS. Can clinical factors predict postoperative temporomandibular disorders in orthognathic patients? A retrospective study of 219 patients. Oral Surg Oral Med Oral Pathol Oral Radiol 2015; 119(5):531-8. https://doi.org/10.1016/j.oooo.2015.01.006

[19] Svedström-Oristo AL, Ekholm H, Tolvanen M, Peltomäki T. Self-reported temporomandibular disorder symptoms and severity of malocclusion in prospective orthognathic-surgical patients. Acta Odontol Scand 2016; 74(6):466-70. https://doi.org/10.1080/00016357.2016.1199815

[20] Manfredini D, Winocur E, Guarda-Nardini L, Paesani D, Lobbezoo F. Epidemiology of bruxism in adults: a systematic review of the literature. J Orofac Pain 2013; 27(2):99-1 10. https://doi.org/10.1 1607/jop.921

[21] Manfredini D, Vano M, Peretta R, Guarda-Nardini L. Jaw clenching effects in relation to two extreme occlusal features: patterns of diagnoses in a TMD patient population. Cranio 2014; 32(1):45-50. https://doi.org/ 10.1179/0886963413Z.0000000009

[22] Hagag G, Yoshida K, Miura H. Occlusion, prosthodontic treatment, and temporomandibular disorders: a review. J Med Dent Sci 2000; 47(1):61-6. https://doi.org/10.11480/jmds.470107

[23] Manfredini D, Peretta R, Guarda-Nardini L, Ferronato G. Predictive value of combined clinically diagnosed bruxism and occlusal features for TMJ pain. Cranio 2010; 28(2):105-13.

[24] Zuaiter S, Robin O, Gebeile-Chauty S, Raberin M. Does dental class II division 2 predispose to temporomandibular disorders? Orthod Fr 2013; 84(3):277-85. https://doi.org/10.1051/orthodfr/2013052

[25] Kataoka K, Ekuni D, Mizutani S, Tomofuji T, Azuma T, Yamane M, et al. Association between self-reported bruxism and malocclusion in university students: a cross-sectional study. J Epidemiol 2015; 25(6):423-30. https://doi.org/10.2188/jea.JE20140180

[26] Farronato G, Rosso G, Giannini L, Galbiati G, Maspero C. Correlation between skeletal Class II and temporomandibular joint disorders: a literature review Minerva Stomatol 2016; 65(4):239-47.

[27] Yeler DY, Yılmaz N, Koraltan M, Aydın E. A survey on the potential relationships between TMD, possible sleep bruxism, unilateral chewing, and occlusal factors in Turkish university students. Cranio 2017; 35(5):308-14. https://doi.org/10.1080/08869634.2016.1239851

[28] Tecco S, Festa F. Prevalence of signs and symptoms of temporomandibular disorders in children and adolescents with and without crossbites. World J Orthod 2010; 11(1):37-42.

[29] Bodine TP, Wolford LM, Araujo E, Oliver DR, Buschang PH. Surgical treatment of adolescent internal condylar resorption (AICR) with articular disc repositioning and orthognathic surgery in the growing patient - a pilot study. Prog Orthod 2016; 17:2. https://doi.org/10.1186/s40510-015-0115-8

[30] Fang B, Shen G, Yang C, Wu Y, Feng Y, Mao L, et al. Changes in condylar and joint disc positions after bilateral sagittal split ramus osteotomy for correction of mandibular prognathism. Int J Oral Maxillofac Surg 2009; 38(7):72630. https://doi.org/10.1016/j.ijom.2009.03.001

[31] Greene CS, Obrez A. Treating temporomandibular disorders with permanent mandibular repositioning: is it medically necessary? Oral Surg Oral Med Oral Pathol Oral Radiol 2015; 119(5):489-98. https://doi.org/ 10.1016/j.oooo.2015.01.020

[32] Song YL, Yap AU. Orthognathic treatment of dentofacial disharmonies: its impact on temporomandibular disorders, quality of life, and psychosocial wellness. Cranio 2017; 35(1):52-7. https://doi.org/ 10.1080/08869634.2016.1147676

[33] Bruguiere F, Sciote JJ, Roland-Billecart T, Raoul G, Machuron F, Ferri J, et al. Pre-operative parafunctional or dysfunctional oral habits are associated with the temporomandibular disorders after orthognathic surgery: an observational cohort study. J Oral Rehabil 2019; 46(4):321-9. https://doi.org/ 10.1111/joor.12749 